\begin{tabular}{|c|c|c|}
\hline & \multicolumn{2}{|c|}{ Journal of Applied Mathematics and Computational Mechanics 2020, 19(3), 17-28 } \\
\hline & www.amcm.pcz.pl & p-ISSN 2299-9965 \\
\hline & DOI: $10.17512 /$ jamcm.2020.3.02 & e-ISSN 2353-0588 \\
\hline
\end{tabular}

\title{
NUMERICAL ANALYSIS OF THE TEMPERATURE IMPACT TO THE OXYGEN DISTRIBUTION IN THE BIOLOGICAL TISSUE
}

\author{
Marek Jasiński \\ Department of Computational Mechanics and Engineering \\ Silesian University of Technology \\ Gliwice, Poland \\ marek.jasinski@polsl.pl
}

Received: 5 June 2020; Accepted: 4 August 2020

\begin{abstract}
The aim of the study was to analyze changes in tissue oxygen distribution resulting from temperature changes by the use of the Krogh cylinder model with Michaelis-Menten kinetics. A Hill model was also used to describe the oxyhemoglobin dissociation curve. In particular, variable values of parameters of dissociation curve and blood velocity in capillary were considered. Mathematical description was based on two separate equations for radial and axial directions. An additional task related to determination of the temperature, tissue thermal damage and perfusion was also solved. At the stage of numerical realization, the finite difference method was used.
\end{abstract}

MSC 2010: 65N06, 76Z05, 80A99, 92C45

Keywords: oxygen transport, Krogh cylinder, oxyhemoglobin dissociation curve, hypoxia, finite difference method

\section{Introduction}

Oxygen is an essential element for life. It is closely related to the release of energy at the cellular level, so it goes without saying that all vital activities of life depend on its presence. It is obtained in the lungs and then transported through the circulatory system to pass into the tissues from the blood in the capillaries. The oxygen content in individual tissues is not constant and may vary depending on many factors, such as the degree of activity of the body, external conditions in which the body is located, or the presence of various substances. Oxygen deficiency is referred to as hypoxia $[1,2]$.

The first model associated with the study of oxygen in the living body was the so-called Krogh cylinder [3], which, despite adopting a number of simplifications [1], allowed to determine the value of oxygen partial pressure in the tissue surrounding the capillary. This model became the basis for many later works, related to, among others, muscle work modelling $[4,5]$, the presence of cancerous tissue 
in the body [6], various therapies [7, 8], the process of angiogenesis and others $[9,10]$.

An increase in tissue temperature may be due to a variety of factors, such as physical exertion, a medical condition, or an external heat impulse. It can affect the body's oxygen balance. While the first two factors often yield reversible effects after the body is restored to normothermia, the heat impulse can lead to irreversible tissue damage.

Thermal damage to tissues is related to, among others, changes in the blood vessels. At a sufficiently high temperature, both larger blood vessels (arterioles, venules) and capillaries are permanently damaged. As already mentioned, the latter are responsible for the supply of oxygen to the tissues. This means that the oxygen level in the tissues changes together with the increase in temperature $[11,12]$.

In the current work, an analysis of changes in tissue oxygen distribution during thermal damage was performed. A model based on the Krogh cylinder concept was considered. Calculations were made for variable parameters of the oxyhemoglobin dissociation curve and the blood velocity in capillaries resulting from the degree of tissue damage. In addition, as determining the degree of thermal damage to the tissue requires knowledge of the temperature field in the tissue, it was determined on a separate model based on the Pennes equation. At the stage of numerical implementation, the finite difference method was used.

\section{The influence of temperature on oxygen transport in tissue}

The relationship between saturation $S_{H b}$, i.e. the content of oxygen in the blood (more precisely in oxyhemoglobin), and partial pressure $P$ is described by the sigmoidal oxyhemoglobin dissociation curve (Fig. 1). It is determined under laboratory conditions, most often for specific temperature values, as well as values of carbon dioxide, $\mathrm{pH}, 2,3-\mathrm{DPG}$ (2,3-diphosphoglycerate) and other substances. The parameter that characterizes the dissociation curve is the $P_{50}$ pressure corresponding to $50 \%$ hemoglobin saturation. An increase in temperature causes the $P_{50}$ value to shift to the right, which is called the right shift effect or Bohr effect $[1,11,12]$.

The dissociation curve is described by various models, among which the Hill model is the most popular $[2,4]$

$$
S_{H b}\left(P_{b}\right)=\frac{P_{b}^{n}}{P_{b}^{n}+P_{50}^{n}}
$$

where $P_{b}[\mathrm{mmHg}]$ is partial pressure of blood and $n$ denotes the Hill coefficient which is related to the slope of dissociation curve. For the normothermia usually $P_{50}=26 \mathrm{mmHg}$ and $n=2.7$ are assumed $[1,2,5]$. Exemplary data of these parameters depending on temperature are presented in the Table 1. 


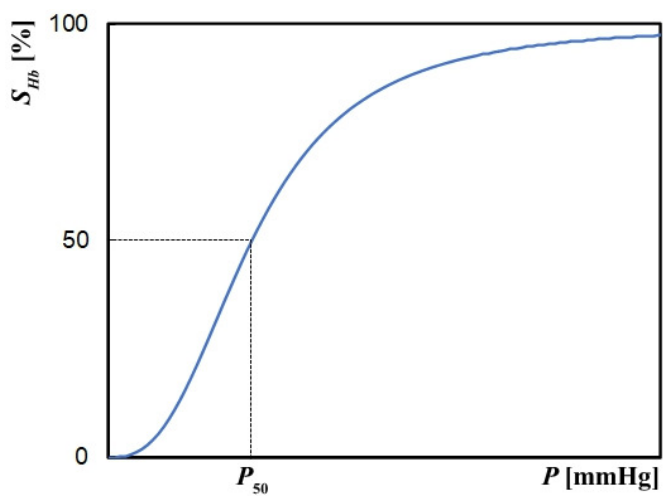

Fig. 1. Oxyhemoglobin dissociation curve

Table 1. Temperature-dependent parameters of Hill model for normal 2,3-DPG level [12]

\begin{tabular}{|c|c|c|c|c|}
\hline$T\left[{ }^{\circ} \mathrm{C}\right]$ & 23 & 30 & 37 & 44 \\
\hline$P_{50}[\mathrm{mmHg}]$ & 12.3 & 17.3 & 27.0 & 35.9 \\
\hline$n$ & 2.39 & 2.35 & 2.57 & 2.45 \\
\hline
\end{tabular}

The impact of increased temperature on tissue may be associated with its damage, which in turn affects the change of tissue perfusion. This can be expressed through a function $[13,14]$

$$
w(A r r)= \begin{cases}\left(1+25 A r r-260 A r r^{2}\right) w_{0}, & 0 \leq A r r \leq 0.1 \\ (1-A r r) w_{0}, & 0.1<A r r \leq 1 \\ 0, & A r r>1\end{cases}
$$

where $w(A r r)$ and $w_{0}$ denote damage-dependent and initial perfusion coefficients $\left[\mathrm{s}^{-1}\right]$ respectively, while Arr is the tissue damage degree estimated on the basis of Arrhenius injury integral [15-17]

$$
\operatorname{Arr}\left(x, t^{F}\right)=\int_{0}^{t^{F}} A \exp \left[-\frac{E}{R T(x, t)}\right] \mathrm{d} t
$$

where $R\left[\mathrm{~J} \mathrm{~mol}^{-1} \mathrm{~K}^{-1}\right]$ is the universal gas constant, $E\left[\mathrm{~J} \mathrm{~mol}^{-1}\right]$ is the activation energy, $A\left[\mathrm{~s}^{-1}\right]$ is the preexponential factor and $T$ is the temperature.

In function (2), interval $[0,0.1]$ means the phase in which, blood vessels expand under the influence of heat, while interval $(0.1,1]$ is associated with progressive damage to blood vessels, meaning a decrease in blood flow. The value of Arr $=1$ is one of the accepted thresholds above which the tissue is permanently damaged.

Changing in tissue perfusion affects parameters associated with the oxygen distribution model, e.g. blood flow rate $\left[\mathrm{cm}^{3} \mathrm{~s}^{-1}\right]$ and blood velocity $\left[\mathrm{cm} \mathrm{s}^{-1}\right]$ [4]. 


\section{Governing equations}

The oxygen distribution model under consideration, based on the Krogh cylinder concept is presented in Figure $2\left(R_{c}\right.$ - capillary radius, $R_{t}$ - tissue cylinder radius, $L$ - length of cylinder, $u_{b}$ - blood velocity in capillary, $r$ and $z$ - radial and axial coordinates).

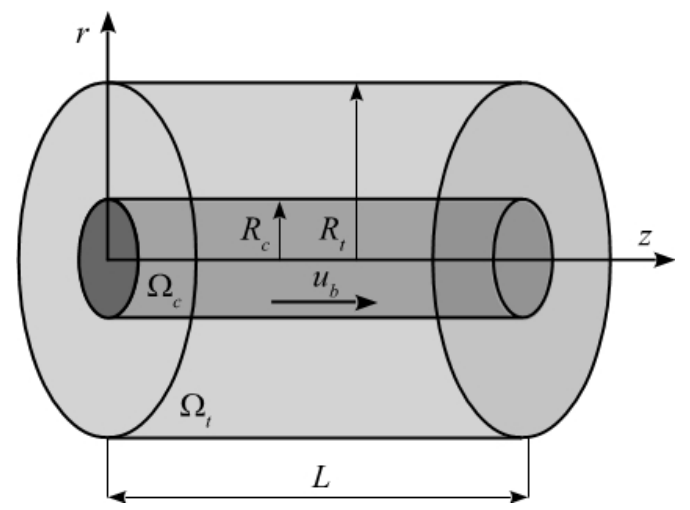

Fig. 2. Domain considered

The distribution of the partial pressure in the tissue subdomain $P_{t}$ is described by the equation [3-5]

$$
\Omega_{t}: \quad K_{t} \frac{1}{r} \frac{d}{d r}\left(r \frac{d P_{t}}{d r}\right)=M_{t}\left(P_{t}\right)
$$

where $K_{t}\left[\left(\mathrm{~cm}^{2} \mathrm{~s}^{-1}\right)\left(\mathrm{cm}^{3}{ }_{\mathrm{O} 2} \mathrm{~cm}^{-3} \mathrm{mmHg}^{-1}\right)\right]$ is the Krogh diffusion coefficient. $M_{t}\left(P_{t}\right)$ on the RHS of (4) is oxygen consumption in tissue which in current work is assumed as Michaelis-Menten kinetics model in form [1]

$$
M_{t}\left(P_{t}\right)=\frac{M_{0} P_{t}}{P_{0}+P_{t}}
$$

where $M_{0}\left[\mathrm{~cm}_{\mathrm{O} 2}^{3} \mathrm{~cm}^{-3} \mathrm{~s}^{-1}\right]$ is oxygen demand while $P_{0}[\mathrm{mmHg}]$ is the partial pressure which correspond to half-maximal oxygen consumption.

Equation (4) is supplemented by boundary conditions in form $[1,2,4]$

$$
\begin{array}{lcl}
r=R_{c}: & 2 \pi R_{c} K_{t} \frac{d P_{t}(r)}{d r}=-k\left[P_{b}-P_{t}(r)\right] \\
r=R_{t}: & \frac{d P_{t}(r)}{d r}=0
\end{array}
$$

where $k\left[\left(\mathrm{~cm}^{2} \mathrm{~s}^{-1}\right)\left(\mathrm{cm}^{3}{ }_{\mathrm{O} 2} \mathrm{~cm}^{-3} \mathrm{mmHg}^{-1}\right)\right]$ is mass transfer coefficient, $P_{b}[\mathrm{mmHg}]$ is the partial pressure in blood 
In axial direction it is assumed that [4]

$$
Q_{b} \kappa_{b} \frac{d\left[S_{H b}\left(P_{b}\right)\right]}{d z}=-k\left(P_{b}-P_{t}\right)
$$

where $Q_{b}\left[\mathrm{~cm}^{3} \mathrm{~s}^{-1}\right]$ denotes blood flow rate in capillary, $\kappa_{b}\left[\mathrm{~cm}^{3}{ }_{\mathrm{O} 2} \mathrm{~cm}^{-3}{ }_{\text {blood }}\right]$ is the oxygen carrying capacity of blood at $100 \%$ saturation.

Equation (7) is supplemented by initial condition

$$
z=0: \quad P_{b}=P_{b \text { inlet }}
$$

After determination of hemoglobin saturation $S_{H b}$ on the basis of (7), the partial pressure in capillary $P_{b}$ is estimated as the inversion of equation (1)

$$
P_{b}=P_{50}\left(\frac{S_{H b}}{1-S_{H b}}\right)^{\frac{1}{n}}
$$

It was already mentioned that, blood flow rate in capillary $Q_{b}$ is associated with perfusion coefficient. Here is assumed that $[4,5]$

$$
w=\frac{Q_{b}}{\pi R_{t}^{2} L_{t}}=\frac{\pi R_{c}^{2} u_{b}}{\pi R_{t}^{2} L_{t}}
$$

so, the blood velocity in capillary is (c.f. equation (2))

$$
u_{b}=w(A r r) L_{t} \frac{R_{t}^{2}}{R_{c}^{2}}
$$

In additional 1D task associated with temperature distribution and damage-dependent perfusion coefficient $w($ Arr $)$ estimation, the Pennes equation with adequate boundary-initial conditions were used, in form $[15,18,19]$

$$
\begin{array}{ll}
x \in \Omega: & c \frac{\partial T}{\partial t}=\lambda \frac{\partial^{2} T}{\partial x}+Q_{m e t}+c_{B} w(A r r)\left[T_{B}-T(x, t)\right] \\
x=0: & q=q_{0}, \quad \text { for } t \leq t_{\text {exp }}, \quad q=\alpha\left(T-T_{a m b}\right), \quad \text { for } t>t_{\text {exp }} \\
x=L_{t}: & q=0 \\
t=0: & T=T_{\text {init }}
\end{array}
$$

where $\lambda\left[\mathrm{Wm}^{-1} \mathrm{~K}^{-1}\right]$ is the thermal conductivity, $c$ and $c_{B}\left[\mathrm{Jm}^{-3} \mathrm{~K}^{-1}\right]$ are the volumetric specific heat of tissue and blood, respectively, $T_{B}$ is the arterial blood temperature, $Q_{m e t}\left[\mathrm{Wm}^{-3}\right]$ is the metabolic heat source, $q_{0}\left[\mathrm{Wm}^{-2}\right]$ is the boundary heat flux, $\alpha\left[\mathrm{Wm}^{-2} \mathrm{~K}^{-1}\right]$ is the convective heat transfer coefficient, $T_{a m b}$ is the temperature of surroundings, $t_{\exp }[\mathrm{s}]$ is the exposure time while $T_{\text {init }}$ denotes the initial distribution of temperature. 


\section{Method of solution}

At the stage of numerical realization the finite difference method has been applied with grid based on three-point stencils $[15,19,20]$.

It was assumed that (c.f. equation (4))

$$
\begin{aligned}
& \frac{1}{r} \frac{d}{d r}\left(r \frac{d P_{t}}{d r}\right)_{i}=\frac{1}{r_{i} h_{r}}\left[\left(r \frac{d P_{t}}{d r}\right)_{i+\frac{1}{2}}-\left(r \frac{d P_{t}}{d r}\right)_{i-\frac{1}{2}}\right]= \\
= & \frac{1}{r_{i} h_{r}}\left[\left(r_{i}+\frac{1}{2} h_{r}\right) \frac{P_{t, i+1}-P_{t, i}}{h_{r}}-\left(r_{i}-\frac{1}{2} h_{r}\right) \frac{P_{t, i}-P_{t, i-1}}{h_{r}}\right]
\end{aligned}
$$

where $h_{r}$ is the grid spacing in radial direction.

Substituting above formula into (4) and after appropriate mathematical manipulation one obtains

$$
\begin{array}{cc}
-\left(\frac{2 \pi R_{c} K_{t}}{h_{r}}+k\right) P_{t, i}+\frac{2 \pi R_{c} K_{t}}{h_{r}} P_{t, i+1}=-k P_{b} & i=0 \\
\beta_{i-1} P_{t, i-1} \frac{P_{0}+P_{t, i}}{P_{t, i}}-\beta_{i} P_{t, i} \frac{P_{0}+P_{t, i}}{P_{t, i}}+\beta_{i+1} P_{t, i+1} \frac{P_{0}+P_{t, i}}{P_{t, i}}=\frac{M_{0}}{K_{t}} & i=1,2, \ldots, n r-1 \\
\frac{1}{h_{r}} P_{t, i-1}-\frac{1}{h_{r}} P_{t, i}=0 & i=n r
\end{array}
$$

where $n r$ is the number of nods in radial direction while

$$
\beta_{i-1}=\frac{1}{h_{r}^{2}} \frac{r_{i}-0.5 h_{r}}{r_{i}} \quad \beta_{i+1}=\frac{1}{h_{r}^{2}} \frac{r_{i}+0.5 h_{r}}{r_{i}} \quad \beta_{i}=\beta_{i-1}+\beta_{i+1}
$$

Because the problem under consideration is non-linear, so additionally the Jacobian matrix have to be determined:

$$
\begin{gathered}
J_{i, i}=-\left(\beta_{i-1} \frac{P_{0} P_{t, i-1}}{P_{t, i}^{2}}+\beta_{i}+\beta_{i+1} \frac{P_{0} P_{t, i+1}}{P_{t, i}^{2}}\right), \\
J_{i, i-1}=\beta_{i-1} \frac{P_{0}+P_{t, i}}{P_{t, i}}, \quad J_{i, i+1}=\beta_{i+1} \frac{P_{0}+P_{t, i}}{P_{t, i}}, \\
J_{0,0}=-\left(\frac{2 \pi R_{c} K_{t}}{h_{r}}+k\right), \quad J_{0,1}=\frac{2 \pi R_{c} K_{t}}{h_{r}}, \\
J_{n r, n r-1}=\frac{1}{h_{r}}, \quad J_{n r, n r}=-\frac{1}{h_{r}}
\end{gathered}
$$


After determination of partial pressure in tissue $P_{t}$ in the radial direction for a given node $m$, saturation $S_{H b}$ is calculated in the next node $m+1$ on the basis (c.f. equation (7))

$$
S_{H b, m+1}=-\frac{k h_{z}}{Q_{b} \kappa_{b}}\left(P_{b, m}-P_{t, m}\right)+S_{H b, m}, \quad m=0,1, \ldots, n z
$$

where $n z$ is the number of nodes in axial direction. Next the partial pressure in capillary $P_{b}$ in the node $m+1$ is also determined by the using of equation (9).

\section{Results of computations}

In task related to determination of the temperature, Arrhenius injury integral and perfusion coefficient (equations (2), (3), (12)) the following data was used: $\lambda=0.75 \mathrm{Wm}^{-1} \mathrm{~K}^{-1}, c=3 \mathrm{MJm}^{-3} \mathrm{~K}^{-1}, c_{B}=3.9962 \mathrm{MJm}^{-3} \mathrm{~K}^{-1}, T_{B}=37^{\circ} \mathrm{C}, Q_{\text {met }}=$ $=250 \mathrm{Wm}^{-3}, q_{0}=15 \mathrm{kWm}^{-2}, \alpha=10 \mathrm{Wm}^{-2} \mathrm{~K}^{-1}, T_{\text {amb }}=20^{\circ} \mathrm{C}, T_{\text {init }}=37^{\circ} \mathrm{C}, t_{\text {exp }}=20 \mathrm{~s}$, $A=3.1 \mathrm{e}+98 \mathrm{~s}^{-1}, E=6.27 \mathrm{e}+5 \mathrm{~J} \mathrm{~mol}^{-1}, R=8.314 \mathrm{~J} \mathrm{~mol}^{-1} \mathrm{~K}^{-1}, \Delta t=0.05 \mathrm{~s}[14,15]$. The value of initial perfusion coefficient was assumed on the basis of estimation of capillary density in muscle as $w_{0}=0.041 \mathrm{~s}^{-1}[4,5]$.

For oxygen distribution model the data assumed were: $R_{c}=2.5 \mu \mathrm{m}, R_{t}=25 \mu \mathrm{m}, L=$ $=500 \mu \mathrm{m}, K_{t}=9.4 \mathrm{e}-10\left(\mathrm{~cm}^{2} \mathrm{~s}^{-1}\right)\left(\mathrm{cm}^{3} \mathrm{O}_{2} \mathrm{~cm}^{-3} \mathrm{mmHg} \mathrm{g}^{-1}\right), M_{0}=0.00667 \mathrm{~cm}^{3} \mathrm{O}_{2} \mathrm{~cm}^{-3} \mathrm{~s}^{-1}$, $k=6.25 \mathrm{e}-9 \quad\left(\mathrm{~cm}^{2} \mathrm{~s}^{-1}\right)\left(\mathrm{cm}^{3} \mathrm{O}_{2} \mathrm{~cm}^{-3} \mathrm{mmHg}^{-1}\right), \quad P_{0}=1 \mathrm{mmHg}, P_{b \text { inlet }}=100 \mathrm{mmHg}$, $\kappa_{b}=0.2 \mathrm{~cm}_{\mathrm{O} 2}^{3} \mathrm{~cm}_{\text {blood }}^{-3}, u_{b}=0.205 \mathrm{~cm} \mathrm{~s}^{-1}$ [4]. Based on the data contained in the Table 1, the following functions for describing the parameters of oxyhemoglobin dissociation curve $P_{50}$ and $n$ were assumed:

$$
P_{50}(T)= \begin{cases}27, & T<37^{\circ} \mathrm{C} \\ 1.27 T-19.99, & T \in\left[37^{\circ} \mathrm{C}, 44^{\circ} \mathrm{C}\right] \\ 35.9, & T>44^{\circ} \mathrm{C}\end{cases}
$$

and

$$
n(T)= \begin{cases}2.57, & T<37^{\circ} \mathrm{C} \\ -0.017 T+3.199, & T \in\left[37^{\circ} \mathrm{C}, 44^{\circ} \mathrm{C}\right] \\ 2.45, & T>44^{\circ} \mathrm{C}\end{cases}
$$

In the first step, the task related to determining the temperature distribution, tissue damage and damage-dependent perfusion coefficient was solved. Then the values determined in this task for the selected node were used to solve tasks related to oxygen distribution.

Figure 3 presents the history of changes of the Arrhenius temperature integral and perfusion coefficient for a node with $x=0.0016 \mathrm{~m}$ coordinate. In this node, the perfusion coefficient increases to the value of $w=0.06564 \mathrm{~s}^{-1}$, after which 
the perfusion drops and finally stabilizes at the value of $w \approx 0.0036 \mathrm{~s}^{-1}$. It should be added that for the node concerned the maximum temperature value was reached for the time $t=21.35 \mathrm{~s}$ and reached $T=57.21^{\circ} \mathrm{C}$. Whereas for $t=60 \mathrm{~s}$ the temperature value was $T=40.56^{\circ} \mathrm{C}$ and values above $44^{\circ} \mathrm{C}$ occurred for $t=6.9-45.25 \mathrm{~s}$.

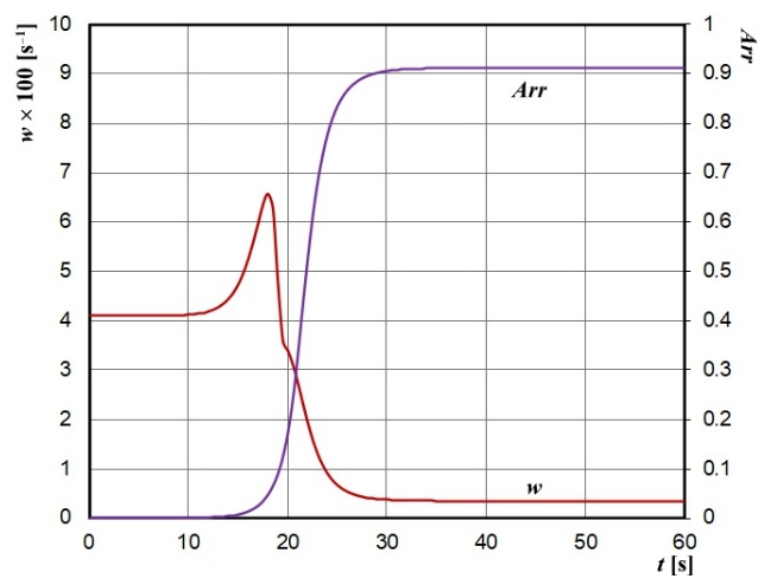

Fig. 3. History of Arrhenius integral and perfusion coefficient at node $x=0.0016 \mathrm{~m}$

On the basis of perfusion coefficient history and equation (11) the blood velocity in capillary $u_{b}$ was calculated for selected time steps: $0,10, \ldots, 60 \mathrm{~s}$. Additionally, $u_{b}$ was determined for time $t=18.05 \mathrm{~s}$, as for the time step when the perfusion coefficient is maximal $\left(w_{\max }\right)$. The calculated values were used in the oxygen distribution model. The following variants of simulation was conducted:

- variant 1: constant $u_{b}$, variable $P_{50}$ and $n$,

- variant 2: variable $u_{b}$, constant $P_{50}$ and $n$,

- variant 3: variable $u_{b}$, variable $P_{50}$ and $n$.

Assumption of the constant parameter values means that their values for $t=0$ are used (i.e. associated with $T_{\text {init }}=37^{\circ} \mathrm{C}, w=w_{0}=0.041 \mathrm{~s}^{-1}$ ), while the variable parameters values are related to $u_{b}$ estimated on the basis of (11) and/or $P_{50}$ and $n$ estimated on the basis of equations (18) and (19). The variant with constant $u_{b}$ and constant Hill curve parameters wasn't considered because it corresponds to the simulations for $t=0$, for each of the considered calculation variants.

Figures 4-6 present calculation results related to oxygen distribution. In all figures related to distribution on radial direction, one curve is visible for $z=0$, which was identical in each simulation (identical $P_{b \text { inlet }}$ value assumed in each simulation) and curves for $z=L / 2$. The pressure drop on the capillary wall is visible in all radial direction curves, while the axial direction curves show the capillary pressure, i.e. $P_{b}$. For variant 2 and 3 , the results indicate the occurrence of hypoxia.

For variant 1 (Fig. 4), due to the functions (18) and (19), the curves for 10-40 s and $w_{\max }$ coincide. It can be stated that in this case the effect of temperature increase causes an increase in pressure in both tissue and capillary. There was no hypoxia in this calculation variant. 
In variant 2 (Fig. 5) for radial direction, the curves for 0 and $10 \mathrm{~s}$ are very close to each other, which results from a similar perfusion coefficient (c.f. Fig. 3), while $P_{t}$ and $P_{b}$ for 40,50 and $60 \mathrm{~s}$ for $L / 2$ is equal to 0 . In the figure for axial direction it can be seen that hypoxia occurred for these times from $z=335 \mu \mathrm{m}$.
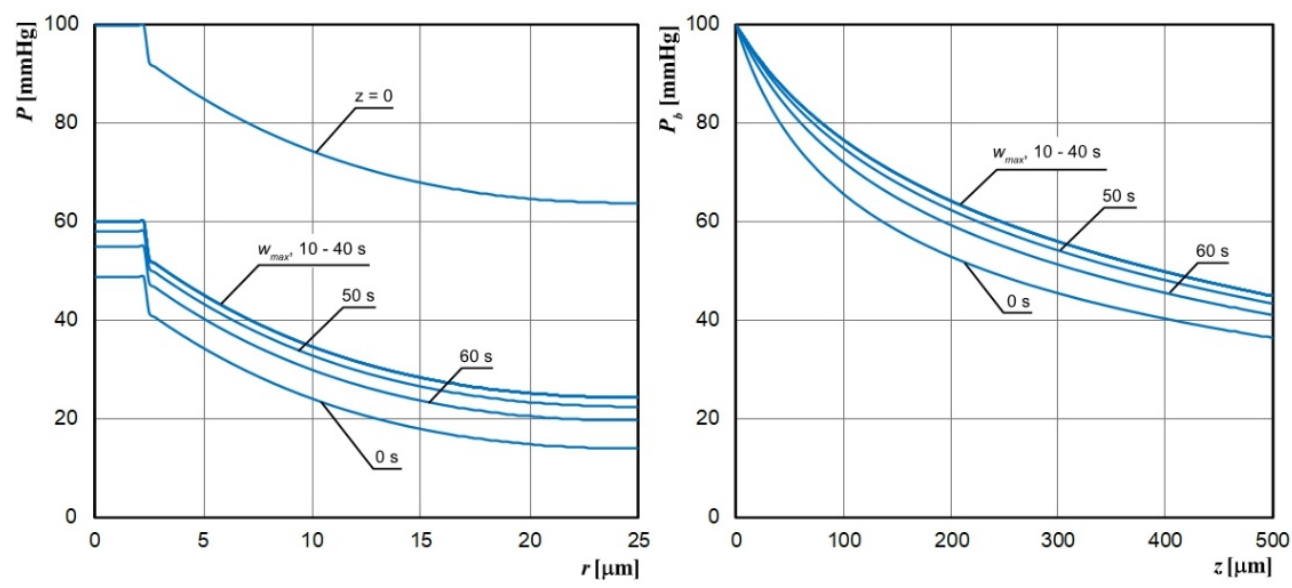

Fig. 4. Distribution of partial pressure in radial and axial directions in variant 1 (constant $u_{b}$, variable $P_{50}$ and $n$ )
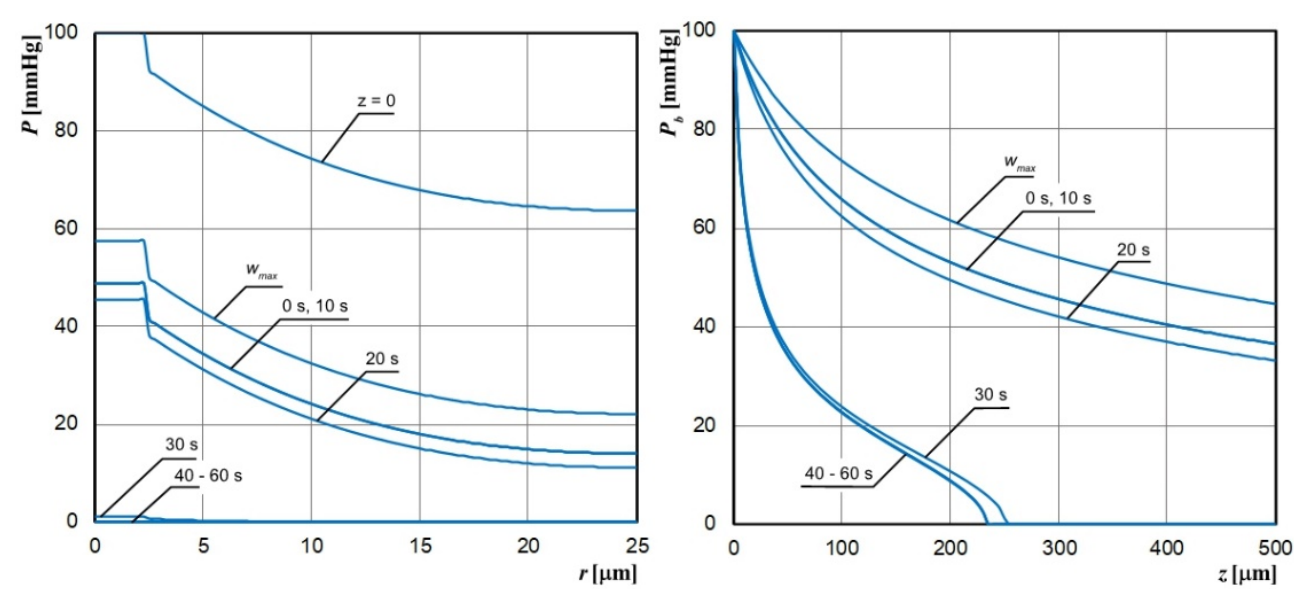

Fig. 5. Distribution of partial pressure in radial and axial directions in variant 2 (variable $u_{b}$, constant $P_{50}$ i $n$ )

For variant 3 (Fig. 6), with variable $u_{b}$ and Hill curve parameters, the highest $P_{b}=69.13 \mathrm{mmHg}$ for $L / 2$ from all simulations was achieved. Just as in variant 2, hypoxia occurred for $t>30 \mathrm{~s}$, therefore $P(L / 2)=0$ for these times. Hypoxia has been reported for $z \approx 200 \mu \mathrm{m}$, i.e. it is larger than in variant 2 . In addition, the influence of variable $P_{50}$ and $n$ is visible here (Table 2). For the times of 30 and $40 \mathrm{~s}$ it can be seen that hypoxia occurs on the increasing length of the capillary, 
after which for the times of 50 and $60 \mathrm{~s}$ it begins to regress, which results from the temperature drop below $44^{\circ} \mathrm{C}$ (equations (18) and (19)).

Table 3 presents a comparison of the hypoxia phenomenon for variants 2 and 3 . The volume of hypoxia was calculated for the subdomain of tissue; it was also assumed that the tissue is hypoxic if $P<1 \mathrm{mmHg}$.
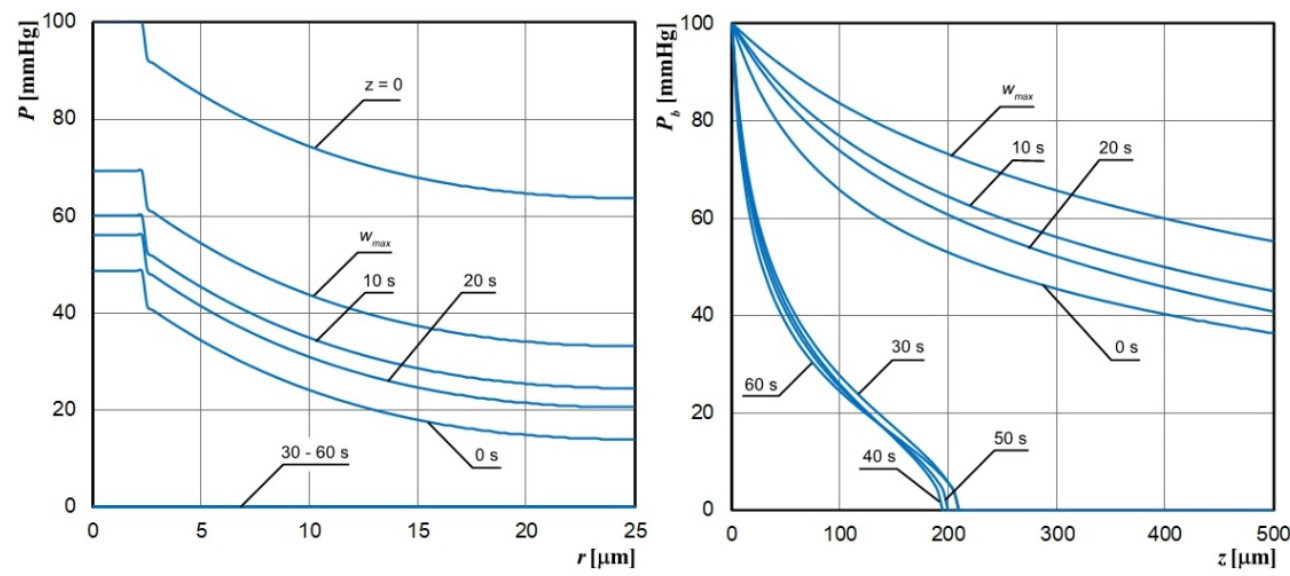

Fig. 6. Distribution of partial pressure in radial and axial directions in variant 3 (variable $u_{b}, P_{50}$ and $n$ )

Table 2. Depth of hypoxia for variant 3 (variable $u_{b}, P_{50}$ and $n$ )

\begin{tabular}{|c|c|c|c|c|}
\hline$t[\mathrm{~s}]$ & $T\left[{ }^{\circ} \mathrm{C}\right]$ & $A r r$ & $w \times 100\left[\mathrm{~s}^{-1}\right]$ & depth of hypoxia $[\mu \mathrm{m}]$ \\
\hline 30 & 51.19 & 0.90546 & 0.3876 & 210 \\
\hline 40 & 45.91 & 0.91200 & 0.3608 & 195 \\
\hline 50 & 42.65 & 0.91221 & 0.3599 & 200 \\
\hline 60 & 40.56 & 0.91224 & 0.3598 & 210 \\
\hline
\end{tabular}

Table 3. Comparison of hypoxia volume in tissue subdomain for variants 2 and 3

\begin{tabular}{|c|c|c|c|c|}
\hline & $30 \mathrm{~s}$ & $40 \mathrm{~s}$ & $50 \mathrm{~s}$ & $60 \mathrm{~s}$ \\
\hline $\begin{array}{c}\text { variant } 2 \\
{[\% \text { of tissue volume }]}\end{array}$ & 64.13 & 66.62 & 66.69 & 66.73 \\
\hline $\begin{array}{c}\text { variant } 3 \\
{[\% \text { of tissue volume }]}\end{array}$ & 66.60 & 68.91 & 68.55 & 67.85 \\
\hline
\end{tabular}

\section{Conclusions}

The considered simulation cases show that the occurrence of the hypoxia phenomenon was mainly influenced by the change in blood velocity resulting from the perfusion coefficient value. The latter was closely related to thermal tissue 
damage through function (2). A drop in the perfusion value causes a simultaneous decrease in blood velocity. The effect of dependence of Hill curve parameters on temperature causes an increase in pressure with increasing temperature. In situations such as those in variant 3 , it can counteract the occurrence of hypoxia.

Many of the parameters used in the simulations were assumed as constant values, e.g. $P_{b \text { inlet }}$ Thermal damage can cause changes at different levels of the vascular network, so it seems that this value should also be accepted as related to tissue damage. It is also worth noting that part of the function (2) is defined in connection with dilatation of the blood vessels $(0.1<A r r \leq 1)$, which in the model related to temperature distribution and determining the degree of tissue damage means an increase in perfusion, while in the oxygen distribution model it could mean a change in diameter of the capillary $R_{c}$.

The current work adopts the dissociation curve model as proposed by Hill. However, it is assumed that this model is accurate mainly in the range of $20-80 \%$ saturation. Because, as the results in the current work show, tissue damage is associated with a drop in saturation often to a level below $20 \%$ of oxygen content in hemoglobin, it seems necessary to use a model that more accurately describes the dissociation curve in this range, e.g. the Adair model [21].

The considered tissue damage process was strictly caused by a thermal impulse. In cases such as photodynamic therapy, we often deal with a mixed photothermal and photochemical mechanism of tissue damage, or even a mechanism limited to photochemical phenomena. Therefore, it can be concluded that in order to replicate the type of processes as accurately as possible, the oxygen distribution model should be supplemented with equations related to chemical reactions in the tissue.

\section{Acknowledgements}

The research is funded from the projects Silesian University of Technology, Faculty of Mechanical Engineering.

\section{References}

[1] Goldman, D. (2008). Theoretical models of microvascular oxygen transport to tissue. Microcirculation, 15, 795-811.

[2] Popel, A.S. (1989). Theory of oxygen transport to tissue. Critical Reviews in Biomedical Engineering, 17, 257-321.

[3] Krogh, A. (1919). The number and distribution of capillaries in muscles with calculations of the oxygen pressure head necessary for supplying the tissue. Journal of Physiology, 52, 409-415.

[4] McGuire, B.J., \& Secomb, T.W. (2001). A theoretical model for oxygen transport in skeletal muscle under conditions of high oxygen demand. Journal of Applied Physiology, 91, 2255-2265.

[5] McGuire, B.J., \& Secomb, T.W. (2003). Estimation of capillary density in human skeletal muscle based on maximal oxygen consumption rates. American Journal of Physiology-Heart and Circulatory Physiology, 285, H2382-H2391. 
[6] He, Y., Shirazaki, M., Liu, H., Himeno, R., \& Sun, Z. (2006). A numerical coupling model to analyze the blood flow, temperature, and oxygen transport in human breast tumor under laser irradiation. Computers in Biology and Medicine, 36, 1289-1378.

[7] Kang-Hsin Wang, K., Finlay, J.C., Busch, T.M., Hahn, S.M., \& Zhu, T.C. (2010). Explicit dosimetry for photodynamic therapy: macroscopic singlet oxygen modeling. Journal of Biophotonics, 3, 5-6.

[8] Zhu, T.C., Liu, B., \& Penjweini, R. (2015). Study of tissue oxygen supply rate in a macroscopic photodynamic therapy singlet oxygen model. Journal of Biomedical Optics, 20, 038001.

[9] Secomb, T.W., Alberding, J.P., Hsu, R., Dewhirst, M.W., \& Pries A.R. (2013). Angiogenesis: an adaptive dynamic biological pattering problem. PLoS Computational Biology, 9, e1002983.

[10] Whiteley, J.P., Gavaghan, D.J., \& Hahn, C.E.W. (2002). Mathematical modelling of oxygen transport to tissue. Journal of Mathematical Biology, 44, 503-522.

[11] Castaing, M., \& Sinet, M. (1980). Temperature and oxygenation of human blood constant total $\mathrm{CO}_{2}$ content. Pflugers Archiv, European Journal of Physiology, 386, 135-140.

[12] Hlastala, M.P., Woodson, R.D., \& Wranne, B. (1977). Influence of temperature on hemoglobinligand interaction in whole blood. Journal of Applied Physiology, 43, 545-550.

[13] Jasiński, M. (2011). Numerical modeling of tissue heating with application of sensitivity methods. Mechanika 2011: Proceedings of the 16th International Conference, 137-142.

[14] Jasiński, M. (2018). Modelling of thermal damage process in soft tissue subjected to laser irradiation. Journal of Applied Mathematics and Computational Mechanics, 17, 29-41.

[15] Korczak, A., \& Jasiński, M. (2019). Modelling of biological tissue damage process with application of interval arithmetic. Journal of Theoretical and Applied Mechanics, 57, 249-261.

[16] Paruch, M. (2018). Identification of the degree of tumor destruction on the basis of the Arrhenius integral using the evolutionary algorithm. International Journal of Thermal Sciences, 130, 507-517.

[17] Paruch, M. (2020). Mathematical modeling of breast tumor destruction using fast heating during radiofrequency ablation. Materials, 13, 136.

[18] Mochnacki, B., \& Ciesielski, M. (2016). Sensitivity of transient temperature field in domain of forearm insulated by protective clothing with respect to perturbations of external boundary heat flux. Bulletin of the Polish Academy of Sciences - Technical Sciences, 64, 591-598.

[19] Mochnacki. B., \& Piasecka-Belkhayat. A. (2013). Numerical modeling of skin tissue heating using the interval finite difference method. Molecular \& Cellular Biomechanics, 10, 233-244.

[20] Majchrzak, E., \& Mochnacki, B. (2016). Dual-phase lag equation. Stability conditions of a numerical algorithm based on the explicit scheme of the finite difference method. Journal of Applied Mathematics and Computational Mechanics, 15, 89-96.

[21] Fletcher, J.E. (1980). On facilitated oxygen diffusion in muscle tissues. Biophysical Journal, 29, 437-458. 